\title{
Educação de Jovens e Adultos - breve análise do panorama brasileiro
}

\author{
Youth and Adult Education - brief analysis of the Brazilian panorama \\ Educación de jóvenes y adultos - breve análisis del panorama brasileño
}

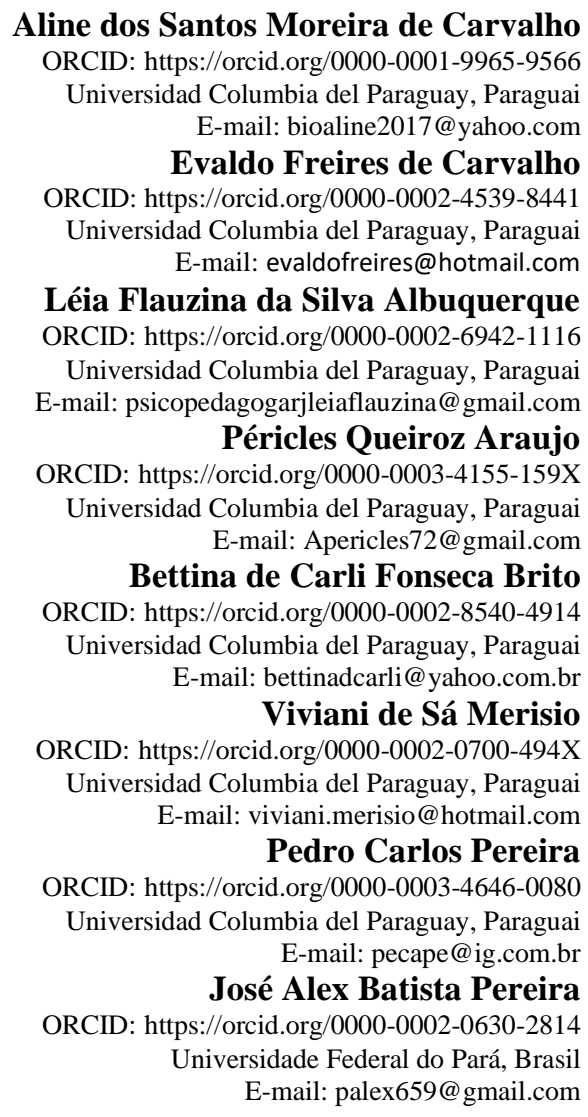

\begin{abstract}
Resumo
A Educação de Jovens e Adultos é uma modalidade específica da Educação brasileira que compreende pessoas maiores de quinze anos que não completaram a Educação Básica em tempo normal ou que jamais frequentaram a escola. A Constituição Federal de 1988 reconhece a educação como direito de todos, independentemente da idade, o que se desdobra em políticas públicas que visam garantir esse direito com igualdade de oportunidades e equidade de ensino. Diante da heterogeneidade que a EJA apresenta e do quantitativo de procura, faz-se necessário por em evidência essa modalidade de ensino para reflexões e discussões. Nesse contexto, o estudo justifica-se essa necessidade e tem por objetivo analisar a EJA brasileira, destacando seu contexto histórico; pontuando as políticas públicas anteriores e atuais; e desenhando um panorama atual da questão. Para tal, utilizou-se de pesquisa de caráter qualitativo. Em relação aos objetivos, é uma pesquisa exploratória e descritiva e no que concerne os procedimentos de pesquisa, o estudo caracterizou-se como bibliográfico. A pesquisa foi realizada em meio virtual, em bases de dados confiáveis, com artigos científicos publicados e inclui também ambientes virtuais de estudos e pesquisas em Direito para embasamento teórico assim como em Leis e na Constituição Federal da República e livros de Pedagogia. Após a leitura analítica e destaque dos aspectos principais, foi elaborada a produção textual em três títulos que se relacionam e complementam: Educação de Jovens e Adultos, EJA; Contexto histórico-legal da EJA no Brasil e Panorama da EJA no Brasil. $\mathrm{O}$ autor buscou manter a impessoalidade, porém suas impressões permeiam as conclusões expostas nas Considerações Finais.
\end{abstract}

Palavras-chave: EJA.; Políticas públicas; Pedagogia. 


\begin{abstract}
Youth and Adult Education is a specific modality of Brazilian Education that comprises people over fifteen years old who have not completed Basic Education in a normal time or who have never attended school. The Federal Constitution of 1988 recognizes education as a right for everyone, regardless of age, which unfolds into public policies that aim to guarantee this right with equal opportunities and equity in education. Given the heterogeneity that EJA presents and the quantity of demand, it is necessary to highlight this teaching modality for reflection and discussions. In this context, the study justifies this need and aims to analyze the Brazilian EJA, highlighting its historical context; punctuating past and current public policies; and drawing a current overview of the issue. For this, a qualitative research was used. Regarding the objectives, it is an exploratory and descriptive research and regarding the research procedures, the study was characterized as bibliographical. The research was carried out in a virtual environment, in reliable databases, with published scientific articles and also includes virtual environments for studies and research in Law for theoretical basis, as well as in Laws and the Federal Constitution of the Republic and Pedagogy books. After the analytical reading and highlighting of the main aspects, the textual production was elaborated in three titles that are related and complement: Youth and Adult Education, EJA; Historical-legal context of EJA in Brazil and Panorama of EJA in Brazil. The author sought to maintain impersonality, but his impressions permeate the conclusions set out in the Final Considerations.
\end{abstract}

Keywords: EJA.; Public policy; Pedagogy.

\title{
Resumen
}

La Educación de Jóvenes y Adultos es una modalidad específica de la Educación Brasileña que comprende a las personas mayores de quince años que no han completado la Educación Básica en un tiempo normal o que nunca han asistido a la escuela. La Constitución Federal de 1988 reconoce la educación como un derecho de todas las personas, independientemente de la edad, que se plasma en políticas públicas que buscan garantizar este derecho con igualdad de oportunidades y equidad en la educación. Dada la heterogeneidad que presenta EJA y la cantidad de demanda, es necesario destacar este tipo de enseñanza para la reflexión y el debate. En este contexto, el estudio justifica esta necesidad y tiene como objetivo analizar la EJA brasileña, destacando su contexto histórico; puntuar las políticas públicas pasadas y actuales; y elaboración de una descripción general actual del problema. Para ello, se utilizó una investigación cualitativa. En cuanto a los objetivos, se trata de una investigación exploratoria y descriptiva y en cuanto a los procedimientos de investigación, el estudio se caracterizó como bibliográfico. La investigación se realizó en un ambiente virtual, en bases de datos confiables, con artículos científicos publicados y también incluye ambientes virtuales para estudios e investigaciones en Derecho con base teórica, así como en Leyes y Constitución Federal de la República y libros de Pedagogía. Luego de la lectura analítica y resaltado de los aspectos principales, se elaboró la producción textual en tres títulos que se relacionan y complementan: Educación para Jóvenes y Adultos, EJA; Contexto histórico-legal de EJA en Brasil y Panorama de EJA en Brasil. El autor trató de mantener la impersonalidad, pero sus impresiones impregnan las conclusiones expuestas en las Consideraciones finales.

Palabras clave: EJA; Políticas públicas; Pedagogía.

\section{Introdução}

A Educação de Jovens e Adultos (EJA) é uma modalidade específica no sistema educacional brasileiro que compreende pessoas maiores de quinze anos que não completaram seus estudos em idade ideal, ou seja, muitos foram evadidos das escolas ou nunca estudaram, considerando o alto nível de analfabetos que se matriculam na EJA.

O Brasil, na Constituição Federal de 1988, em seu artigo 208, reconhece a educação como direito de todos. Esse artigo prevê como dever do Estado a garantia do Ensino Fundamental, obrigatório e gratuito, a despeito da idade (Brasil, 1988).

Nesse sentido e diante do contexto da heterogeneidade e quantidade de pessoas matriculadas na EJA, é necessário colocar essa modalidade de ensino em pauta de assuntos educacionais, políticas públicas, metodologias de ensino assim como de práticas pedagógicas, entre outros.

A EJA é uma modalidade de ensino recente no Brasil, pois começou sua história nos anos 40 (como um modelo assistencialista) e desde então vem sendo transformada e inovada de acordo com políticas públicas eu visam garantir igualdade, democratização e equidade para aqueles que não puderam terminar a educação básica em tempo normal.

Nessa perspectiva, o estudo justifica-se por haver a necessidade de colocar a EJA em evidência para discussões e reflexões e tem por objetivo analisar a EJA brasileira, destacando seu contexto histórico; pontuando as políticas públicas anteriores e atuais; e desenhando um panorama atual da questão. 
Para tal, utilizou-se de pesquisa de caráter qualitativo, pois tal abordagem oferece e possibilita uma visão para [...] o universo dos significados, dos motivos, das aspirações, das crenças, dos valores e das atitudes." (Minayo et al., 2009, p. 21).

Em relação aos objetivos, é uma pesquisa exploratória e descritiva (Gil, 2008) pois busca descrever a situação real e atual da EJA brasileira no contexto de política pública.

No que concerne os procedimentos de pesquisa, o estudo caracterizou-se como bibliográfico que, segundo Gil (2008), é desenvolvida com base em material já elaborado, principalmente em artigos científicos e livros. A pesquisa foi realizada em meio virtual, em bases de dados confiáveis, com artigos científicos publicados e inclui também ambientes virtuais de estudos e pesquisas em Direito para embasamento teórico assim como em Leis e na Constituição Federal da República e livros de Pedagogia.

Após a leitura analítica e destaque dos aspectos principais, foi elaborada a produção textual em três títulos que se relacionam e complementam: Educação de Jovens e Adultos, EJA; Contexto histórico-legal da EJA no Brasil e Panorama da EJA no Brasil.

O autor buscou manter a impessoalidade, porém suas impressões permeiam as conclusões expostas nas Considerações Finais.

\section{Educação de Jovens e Adultos, EJA}

A Educação de Jovens e Adultos é um solo fértil para práticas e reflexões que agregam novos significados excedentes aos limites da escolarização, como naturalmente conceituada, porque compreende diversos processos de formação que incluem qualificação profissional, desenvolvimento comunitário e de cidadania, formação política e questões culturais múltiplas envolvendo pluralidade de espaços que não os escolares (Pierro et al., 2001).

Um campo educacional rico, onde podem ser desenvolvidas inovações pedagógicas práticas e teóricas. Porém durante uma observação pautada em cunho educativo mais restrito, a EJA recebe um conceito de ser entendida como marginal ou secundária, ou seja, não fundamental para o processo e não interessante para visões políticas e pedagógicas ao passo que, vista através de um olhar amplo e sistêmico, a EJA faz parte da história da educação brasileira, tendo por um dos objetivos, a democratização do conhecimento (Pierro et al., 2001).

Segundo Vasques et al. (2019), refletir sobre a Educação de Jovens e Adultos, ou seja, essa modalidade e públicos específicos, coloca em pauta de discussão as suas funções e finalidades específicas, e o aspecto democrático da escola, sobre as quais Freire (2001 apud Vasques et al., 2019) defende como um ato político e de conhecimento, onde devem ser avaliadas e levadas em consideração as diferentes realidades encontradas, para que esses possa verdadeiramente tomar propriedade sobre a leitura, o que os imerge no contexto social geral, letrado e participativo.

A Educação de Jovens e Adultos (EJA) é a designação para uma modalidade de ensino que consiste em atender a necessidade do ensino de pessoas que não estejam em idade escolar. A EJA perpassa todos os níveis do ensino básico e, comumente, abarca cidadãos economicamente ativos, trabalhadores e trabalhadoras, empregados ou não, que, na sua maioria, não tiveram oportunidade de concluir o ensino básico no tempo escolar indicado pelo Ministério da Educação (MEC) (Salgado, 2012).

Dentre as muitas razões que levam jovens e adultos a evadirem a escola ou trancarem suas matrículas na idade correta das séries, a mais comum é a necessidade de complementar a renda familiar, ingressando no mercado de trabalho, havendo ainda outros fatores como as sucessivas reprovações e as questões extraescolares que, por sua vez, englobam razões de cunho social ou subjetivo, como, por exemplo, gravidez precoce, proibição do cônjuge, desmotivação em estudar, entre outras (Salgado, 2012). 


\section{Contexto histórico-legal da EJA no Brasil}

Segundo Vasques et al., (2019), deve-se destacar que jovens e adultos têm seu tempo de direito à Educação assim como toda e qualquer pessoa, por ser este um direito constitucional e fundamental.

Neste sentido, observa-se que aquele não foi ainda plenamente legitimado, na prática, pela sociedade e pelo poder público assim como destaca-se que o campo de atuação para aquisição de conhecimentos é uma sociedade multicultural. Visto que a escola é o lugar onde ocorre a escolarização para preparar para o futuro profissional, pode-se dizer que é heterogênea em realidades, contextos, pensamentos e que concentra diálogos, aprendizagens, discussões, desenvolvimento de ideologias, criatividade e construção de saberes, fomentando questionamentos sociais que tornam os discentes ativos na sociedade e transformadores de realidades (Vasques et al., 2019).

No decorrer da história da educação formal no Brasil, é sabido que pobres e escravos foram excluídos desse contexto. A educação de jovens e adultos torna-se política educacional nos anos 40 , recebendo atenção, através de iniciativas concretas, devido a preocupação de oferecer escolarização a camadas sociais até então excluídas do contexto escolar, o que provocou diversas ações governamentais entre os anos 40 e 50, podendo ser citadas: "a criação do Fundo Nacional de Ensino Primário em 1942, do Serviço de Educação de Adultos e da Campanha de Educação de Adultos, ambos em 1947, da Campanha de Educação Rural iniciada em 1952 e da Campanha Nacional de Erradicação do Analfabetismo em 1958" (Pierro et al., 2001, p. $59)$.

De acordo com Beisiegel (1997) apud Pierro et al., 2001), destaca a Campanha Nacional de Educação de Adultos iniciada em 1947, por seu caráter exemplar como política pública que refletia o entendimento de que a educação de jovens e adultos como essência para aumentar o nível educacional da população como um todo.

O incentivo financeiro do Estado colaborou para o desenvolvimento de educação básica para jovens e adultos nos anos 60, criando o supletivo integrado às estruturas educacionais estaduais (Pierro et al., 2001).

O II Congresso Nacional de Educação de Adultos, no Rio de Janeiro, contou com a presença do Presidente da República, repartições públicas e privadas e atribuiu à Educação de Jovens e Adultos a devida importância para o crescimento econômico, atrelada à capacitação profissional técnica para atender às demandas da sociedade moderna por mão de obra. Ainda nesse, outros aspectos relevantes foram pontuados como a necessidade da continuação dos estudos, dando origem aos Sistemas Supletivos Estaduais. (Salgado, 2010).

Em 1960, os resultados de Campanhas como a de Educação de Adolescentes e Adultos - CEEA que, antes de ser extinta em 1963, expandiu-se para o Rádio através do sistema Rádio Educativo Nacional, contribuindo para a regulamentação da gratuidade do rádio para a transmissão de programas educativos em todo país, o que fez nascer o Projeto Minerva de Rádio Educação (Salgado, 2010).

A partir da Segunda Conferência Internacional de Adultos em Montreal de 1963, a EJA passa a constar como continuação da educação formal permanente e como educação de base ou comunitária. Nesse período, essa modalidade educacional recebeu caráter assistencialista, caracterizado por ações sociais, pelas igrejas e pelo Governo Federal embasados pelas campanhas de mobilização educacionais (Salgado, 2010).

Entre 1946 e 1964 movimentos de educação popular ganham destaques, marcando a História pela atuação de diferentes grupos sociais comprometidos com a população mais pobre. Todavia, parte significativa da população brasileira se mantinha analfabeta (Salgado, 2010).

Em 1970, surge o Movimento Brasileiro de Alfabetização - MOBRAL, criado pela lei 5.379 de 1967, uma iniciativa do governo que buscava atender a demanda do analfabetismo mundial, urgência fortalecida e apressada pela UNESCO a fim de integrar jovens e adultos à sociedade compreendendo aspectos de leitura, escrita e cálculos, assegurando o fundamental para que pudessem melhorar a qualidade de mão de obra oferecida (Salgado, 2010). 
O método do MOBRAL levado para todas salas de aula no Brasil, propunha a utilização de estratégias já antes utilizadas pelos movimentos populares de alfabetização das massas, como, por exemplo, uma das fases da alfabetização pregada por Freire - o recurso das palavras geradoras, que compreende a ideia de que o vocábulo, mesmo não fazendo sentido nos livros, nos cadernos e nos quadros, é apresentado ao aluno no contexto da sua regionalidade, tornando o conteúdo significativo e, consequentemente, o processo produtivo (Freire, 2014).

A educação da elite sempre prevaleceu à educação das massas, assim sendo, a medida em que a primeira proporciona uma condição diferenciada ao aluno, dando-lhe opção quanto ao que escolher no futuro enquanto que a segunda, pelo seu próprio formato, prepara mão de obra trabalhadora e braçal que atenda às necessidades do modo de produção capitalista (Salgado, 2012).

As diferenças de educação de crianças e adolescentes para jovens e adultos como idade, vivências, estímulos e assimilação do conhecimento culminou na necessidade de se estabelecer uma prática pedagógica consonante a esse segmento, sendo estabelecida na Lei 9.394 de 1996, conhecida como a Lei de Diretrizes e Bases da Educação (LDB) em sua seção V, artigo 37, que descreve:

Art. 37. A educação de jovens e adultos será destinada àqueles que não tiveram acesso ou continuidade de estudos nos ensinos fundamental e médio na idade própria e constituirá instrumento para a educação e a aprendizagem ao longo da vida (Brasil, 1996).

$\mathrm{O}$ artigo $4^{\circ}$, inciso VII, descreve:

VII - oferta de educação escolar regular para jovens e adultos, com características e modalidades adequadas às suas necessidades e disponibilidades, garantindo-se aos que forem trabalhadores as condições de acesso e permanência na escola (Brasil, 1996).

A LDB também integrou uma mudança conceitual sobre a EJA, que Soares (2002, p. 08 apud Vasques et al, 209, s.p.) interpretou como:

A mudança de "ensino supletivo" para "Educação de Jovens e Adultos" não é mera atualização vocabular. Houve um alargamento do conceito ao mudar a expressão de ensino para educação. Enquanto o termo "ensino" se restringe à mera instrução, o termo "educação" é muito mais amplo, compreendendo os diversos processos de formação.

Em relação ao que a legislação pressupõe, existem aspectos que dão suporte ao jovem e ao adulto no processo escolar. Na Lei de Diretrizes e Bases da Educação Nacional e o Plano Nacional de Educação em vigor, existem normativas estabelecidas mediante decisões sobre diretrizes da educação EJA em âmbito internacional que apontam temas atuais e são ponto de partida para políticas públicas a serem desenvolvidas em relação a essa modalidade de ensino e a esse público diferenciado (Brasil, 1996; Brasil, 2014).

A EJA, na escola, pressupõe a releitura da sociedade, trazendo novas formas de educação para reinventar o mundo, antecipando a educação de uma sociedade que luta pelo fim das desigualdades e ela liberdade de aprender, e potencializa o desejo de transformação social, gerando autonomia e independência individuais e coletivas (Vasques et al., 2019).

Sendo assim, em 200, o Parecer 11 regulamentou as Diretrizes Curriculares da Educação EJA que a qualifica e define algumas de suas funções como: reparadora, equalizadora e qualificadora. Nessa perspectiva, Soares (2002 apud Vasques et al., 2019) descreve cada uma das funções, esclarecendo acerca do Parecer 11 (Brasil, 2000, p. 34-41 apud Soares, 2002 apud Vasques et al., 2019):

A função reparadora da EJA, no limite, significa não só a entrada no circuito dos direitos civis pela restauração de um direito negado: o direito a uma escola de qualidade, mas também o reconhecimento daquela igualdade ontológica de todo e qualquer ser humano (p. 34). 
(...) A função equalizadora da EJA vai dar cobertura a trabalhadores e a tantos outros segmentos sociais como donas de casa, migrantes, aposentados, encarcerados. A reentrada no sistema educacional dos que tiveram uma interrupção forçada seja pela repetência ou pela evasão, seja pelas desiguais oportunidades de permanência ou outras condições adversas, deve ser saudada como uma reparação corretiva, ainda que tardia, de estruturas arcaicas, possibilitando aos indivíduos novas inserções no mundo do trabalho, na vida social, nos espaços da estética e na abertura de canais de comunicação (p. 38).

(...) Essa tarefa de propiciar a todos a atualização de conhecimentos por toda a vida é função permanente da EJA que pode se chamar de qualificadora. Mais do que uma função ela é o próprio sentido da EJA.

Sendo assim, autores defendem que a garantia de vagas em EJA, muito mais que política pública, trata-se de um direito conquistado pela sociedade através de lutas, organizações e movimentos sociais, assim como apoio de entidades internacionais e deve aumentar sua percentagem de participação no contexto social e gerar autonomia, pois aquela pressupõe um modelo pedagógico próprio que atenda às necessidades específicas e que tenha flexibilização de currículo (Vasques et al., 2019).

\section{Panorama da EJA no Brasil}

O Brasil, atualmente tem buscado investir na EJA, cujo público atendido compreende pessoas acima de quinze anos que não completaram a educação básica em tempo ideal. Essa modalidade educativa depende, principalmente, de ações desenvolvidas pelos Estados e pelo Governo como políticas públicas que visam garantir os direitos constitucionais a esses cidadãos (Salgado, 2012).

As políticas públicas do Estado uma vez sendo normatizadas, são transformadas em leis, dentre elas, desde o ano 2000 temos: Brasil Alfabetizado; PROJOVEM; PROEJA; PRONERA e Escola de Fábricas, entretanto devemos observar que nas últimas décadas, na História da Educação Brasileira, são elaboradas políticas públicas que atendem a população em geral (Salgado, 2012).

Nota-se a necessidade de observar que algumas políticas públicas são de caráter recompensador ou compensatório, voltadas a atender as mais variadas classes sociais em momentos distintos, pois dentro do Modo de Produção Capitalista, as políticas tendem a favorecer o capitalismo e suas demandas, logo, a educação será favorecida e favorecedora quanto aos seus objetivos.

Conforme Rummert e Ventura (2007, p. 13 apud Casques et al., 2019):

O caráter utilitarista e empobrecido da concepção de educação proposta para os jovens e adultos brasileiros está amplamente coerente com a opção de sermos uma economia inserida no mercado mundial de forma associada e subordinada às nações centrais, posição que nos coloca predominantemente ligados às atividades econômicas neuromusculares, as quais necessitam de pouco investimento em educação. Trata-se de uma concepção de Educação para Jovens e Adultos trabalhadores restrita às necessidades do modelo societário do capital, que nos coloca, predominantemente, como consumidores e não como produtores de tecnologia.

Nessa perspectiva, autores defendem que a Educação de Jovens e Adultos possui ainda um caráter assistencialista, como um mitigador da não escolarização devido a evasão escolar na idade correta. Contudo, o observado na realidade brasileira, essa como não cumpridora da totalidade os seus objetivos acarretando o abandono da escola nesse período (Vasques et al., 2019). 


\section{Considerações Finais}

A modalidade de ensino de Jovens e Adultos durante muito tempo foi compreendida apenas como política pública, porém há novas significâncias quanto a sua funcionalidade e objetivos que vem transformando a qualidade de ensino e como esse é desenvolvido nessas classes.

Observa-se que a educação de jovens e adultos conta com uma riqueza própria do grupo em questão, principalmente do jovem que retorna à escola nessa fase da vida, repensa seu lugar e posição social, e, nesse sentido, a escola pode projetá-lo como sujeito de transformação.

Sendo assim, esse público espera mais dos professores cujo discurso também é o de transformação, sobretudo, para confrontar com o contexto sócio histórico atual capitalista.

Portanto, as políticas públicas são necessárias para a democratização da educação, diminuição das desigualdades e promoção da equidade assim como de autonomia da população para transformação social, porém a EJA significa mais, para o individual, um sonho realizado e para o coletivo uma esperança transformadora da sociedade.

\section{Referências}

Antunes, D. D. (2006). Relatos significativos de professores e alunos na Educação de Jovens e Adultos e sua auto-imagem e auto-estima. Tese de Mestrado pela Pontifícia Universidade Católica do Rio Grande do Sul.

Beisiegel, C. de R. (1999) Considerações sobre a política da União para a educação de jovens e adultos analfabetos. Revista Brasileira de Educação, (4), 2634.

Brasil. (1996). Ministério da Educação. Lei de Diretrizes e Bases da Educação Nacional. LEI N 9.394 de 20 de dezembro de 1996. http://portal.mec.gov.br/seesp/arquivos/pdf/lei9394_ldbn1.pdf.

Brasil, Ministério da Educação. Plano Nacional de Educação. Lei n n 13.005/2014. Brasília, 2014. https://pne.mec.gov.br/18-planos-subnacionais-deeducacao/543-plano-nacional-de-educacao-lei-n-13-005-2014.

Fávero, O., Rummert, S. M., \& Vargas, S. de. (1999). Formação de profissionais para a educação de jovens e adultos trabalhadores: A proposta da faculdade de educação da Universidade Federal Fluminense. In: Diversidade e desigualdade: Desafios para a educação na fronteira do século. $22^{\mathrm{a}}$ Reunião Anual da Anped, São Paulo, FLECHA GARCIA, Ramon. Efeito desnivelador y educación comunicativa: Educación de jovenes y personas adultas en España. Crea, 1996.

Freire, P. (1987). Pedagogia do Oprimido. Paz e Terra.

Freire, P. (2014). Pedagogia da Autonomia: Saberes Necessários à Prática Educativa. Paz e Terra.

Gil, A. C (2008). Métodos e técnicas da pesquisa social. (6a ed.), Atlas.

Linâneo, J. C. (2007). Pedagogia e Pedagogos, Para Quê? Cortez.

Manfredi, S. M. (1981). Política e Educação Popular. (2a ed.), Ed. Cortez.

Medeiros, M. S. de A. (1999) A Formação de Professores para a Educação de Adultos no Brasil: da história à ação. Palma de Malorca: Tese de Doutorado pela Universitat de les Illes Balears.

Minayo, M. C. de S., et al (2009). (Org.). Pesquisa Social: teoria, método e criatividade. (28a ed.), Vozes.

Pierro., M. C. et al. Visões da Educação de Jovens e Adultos no Brasil. Cadernos Cedes, ano XXI, n 55 , Brasil, novembro/2001. https://www.scielo.br/j/ccedes/a/44R8wkjSwvn8w6dtBbmBqgQ/?format=pdf\&lang=pt..

Ribeiro, V. M. Masagão. Alfabetismo e atitudes: Pesquisa junto a jovens e adultos. Ação Educativa/Papirus, 1998.

Ribeiro, V. M. Masagão et al. Educação de jovens e adultos: Proposta curricular para o $1^{o}$ segmento do ensino fundamental. Ação Educativa/MEC-SEF, 1997.

Salgado, E. N. (2010) Educação de Jovens e Adultos. 1 / Edmée Nunes Salgado; Paulo Corrêa Barbosa. Rio de Janeiro: Fundação CECIERJ.

Santos, E. A. A. dos; Stremel, M. L. K.; Oliveira, R. de C. da S. (2004). A Necessidade de Reinventar a História da Educação de Jovens e Adultos no Brasil. Universidade Estadual de Ponta Grossa - UEPG, http://www.cereja.org.br/arquivos_upload/edicleia_margareth_rita_necessidade_\% 20reinventar_eja.pdf

Stephanou, M.; \& Bastos, M. H. (2005). Histórias e Memórias da Educação no Brasil. III. Vozes.

Vasques, C. C. et al., Políticas públicas para a Educação de Jovens e Adultos (EJA). Revista Educação Pública, 19 , no 16 , 13 de agosto de 2019. <https://educacaopublica.cecierj.edu.br/artigos/19/16/politicas-publicas-para-a-educacao-de-jovens-e-adultos-eja-a-escola-como-local-de-excelencia-para-arealizacao-dos-processos-de-ensino-e-aprendizagem $>$. 